\title{
Dizel, Dizel/Biyodizel ile Çalışan Bir Motora Kütlece Asetilen Gazı İlavesinin Etkileri
}

\author{
Salih ÖZER ${ }^{1}$, Erdinç VURAL ${ }^{2 *}$, Serkan ÖZEL $^{3}$ \\ ${ }^{1}$ Muş Alparslan Üniversitesi, Mühendislik Mimarlkk Fakültesi, Makine Mühendisliği Bölümü, Muş \\ ${ }^{2}$ Aydın Adnan Menderes Üniversitesi, Germencik Yamantürk Meslek Yüksekokulu, Aydın \\ ${ }^{3}$ Bitlis Eren Üniversitesi, Mühendislik Mimarlık Fakültesi, Makine Mühendisliği Bölümü, Bitlis \\ (ORCID: 0000-0002-6968-8734) (ORCID: 0000-0002-3398-5593) (ORCID: 0000-0003-0700-1295)
}

\begin{abstract}
Özet
$\mathrm{Bu}$ çalışma da tek silindirli, sıkıștırma ile ateșlemeli, direk enjektörlü motora sahip bir dizel jeneratörde dizel yakıtına $\% 50$ biyodizeli ve dizel yakıt karışımına kütlece $\% 10$ ve $\% 20$ oranında asetilen gazı ilavesinin egzoz gazı sıcaklığına, yakıt tüketim değerine ve egzoz emisyonlarına (NOx, CO, is ve $\mathrm{HC}$ ) etkisi incelenmiştir. Asetilen gazı bir kütlesel akış metre ile motorun emme manifoltundan gaz halinde dizel yakıt ile eş zamanlı olarak verilmiştir. $\mathrm{Bu}$ işlemler jeneratörün $1000 \mathrm{~W}, 2000 \mathrm{~W}, 3000 \mathrm{~W}$ ve $4000 \mathrm{~W}$ güç üreteceği koşullarda tekrarlanmıştır. Tüm sabit şartlar altında deneyler üçer kez tekrar edilerek sonuçların ortalamaları alınmıştır. Asetilen gazı ilavesi ile yakıt tüketim değeri, egzoz gazı sıcaklığı, NOx emisyonları artarken, HC, CO ve is emisyonları azalmıştır.
\end{abstract}

Anahtar kelimeler: Alternatif enerji, asetilen gazı, motor performansı, egzoz emisyonu.

\section{The Effects of Mass Addition of Acetylene Gas to a Diesel, Diesel/Biodiesel Powered Engine}

\begin{abstract}
In this study, single-cylinder, compression ignition, direct diesel generator engine diesel fuel with a marinade of $50 \%$ biodiesel and diesel fuel mixture, by Mass, $10 \%$ and $20 \%$ acetylene gas addition, exhaust gas temperature, fuel consumption and exhaust emissions ( $\mathrm{NOx}, \mathrm{CO}$, and $\mathrm{HC}$ business) effect was investigated. Acetylene gas is supplied simultaneously with gaseous diesel fuel from the intake manifold of the engine with a mass flow meter. These operations were repeated in conditions where the generator would produce $1000 \mathrm{~W}, 2000 \mathrm{~W}, 3000 \mathrm{~W}$ and $4000 \mathrm{~W}$ of power. Under all fixed conditions, the experiments were repeated three times and the results were averaged. With the addition of acetylene gas, fuel consumption value, exhaust gas temperature, NOx emissions increased, while $\mathrm{HC}, \mathrm{CO}$ and is emissions decreased.
\end{abstract}

Keywords: Alternative energy, acetylene gas, engine performance, exhaust emission.

\section{Giriș}

Enerji, toplum, insan yaşamı, ülkelerin ekonomik, ticari ve sosyal alanlardaki refahın arttırılmasında vazgeçilmez bir etken olmaya devam etmektedir. Bu nedenle enerji ihtiyacına sürekli olarak cevap verecek kaynaklar ve bu kaynakların devamlılığı önemlidir. İnsanoğlu teknolojinin gelişmesi ile birlikte enerji üretiminde tek bir kaynağa bağımlı kalmak yerine alternatif enerji kaynağı arayışları içerisine girmiştir. Örneğin günümüzde elektrik enerjisinin üretiminde kömür, doğalgaz, su kaynakları, jeotermal, nükleer kaynaklar, güneş, rüzgâr vb. gibi geniş bir kaynak çeşitliliği mevcuttur. Çünkü ülkeler enerji üretiminde tek bir enerji kaynağına bağlı kalmak istememektedirler [1]. Elektrik enerjisi, elektrik santrallerinde, değişik yakıtların gücünün kullanılması ile üretilebildiği gibi evlerde ya da iş yerlerinde küçük ebatlı üreteçlerin kullanılması ile de üretilebilmektedir. Temel amaç bir elektrik üreteci olan alternatörün bir güç vasıtasıyla döndürülmesidir. Bu üreteçler bazen bir içten yanmalı motor, bazen

"Sorumlu yazar:erdinc009@ hotmail.com

Geliş Tarihi: 26.12.2019, Kabul Tarihi: 20.04.2020 
rüzgâr enerjisi ya da suyun gücü ile döndürülmektedir [2]. Jeneratörler, bir elektrik üretici ve içten yanmalı motorun kullanılması ile elektrik üretimini sağlayan araçlardır. Günümüzde evlerde ve iş yerlerinde kullanılan jeneratörlerden büyük şehirlerin elektrik ihtiyacını karşılayan jeneratörlere kadar birçok yerde kullanıma açılan bu araçlarda alternatörün döndürülme işlemi içten yanmalı motorlar sayesinde yapılmaktadır [3]. İçten yanmalı motorlar ise silindir içerisine alınan hava+yakıt karışımının yakılması ile hareket enerjisi üreten makinelerdir. Bu hareket motorlu araçlarda arabanın gitmesini, küçük el aletlerinde iş yapma hareketini, jeneratörlerde ise elektrik üretecinin döndürülmesini sağlayan güç kaynağıdır. Bu güç kaynaklarında kullanılan yakıtların çevreci, ekonomik ve yerli kaynaklarla üretilir olması ülkelerin enerji darboğazındaki çıkmazını değiştirebilecek önemli bir adımdır. $\mathrm{Bu}$ nedenle içten yanmalı motorlarda alternatif enerji kaynaklarının kullanımı ile ilgili yapılan birçok çalışma mevcuttur. Özellikle üretimi ucuz, çevreci ve milli kaynaklarla üretimi gerçekleştirilebilecek olan yakıtların kullanımı üzerinde durulmakta ve bu alanda yapılan çalışmalara hız verilmektedir $[4,5]$. Asetilen gazı, günümüzde kaynak ve metal kesme işlemlerinde kullanılan isıl değeri yüksek bir gaz türüdür. Asetilen karpit taşının su ile reaksiyona girmesi sonucu oluşmaktadır. Asetilen gazı zehirsiz ve kokusuz bir gaz olmasının yanında çabuk yanabilen ve tutuşabilen bir gaz türüdür. Asetilenin yüksek oranda 1sıl enerjiye sahip olması son yıllarda asetilen ile ilgili yapılan çalışmaların sayısının artmasına neden olmuştur [6-8]. Literatürde asetilen ile yapılan çalışmaların bazıları özetlenmeye çalışılmıştır. İlhak ve ark. [9]. Benzine $500 \mathrm{~g} / \mathrm{h}$ ve $1000 \mathrm{~g} / \mathrm{h}$ asetilen gazı ilavesinin dört silindirli dört zamanlı bir motorda, motor performansına ve egzoz emisyonlarına etkisini incelemişlerdir. $1500 \mathrm{~d} / \mathrm{dak}$ motor hızında $\% 25$ ve $\% 50$ motor yüklerinde kütlesel bir debimetre yardımı ile emme manifolduna istenilen miktardaki asetilen gazını göndermişlerdir. Benzine asetilen gazı ilavesi ile birlikte termal verimin azaldığını, egzoz gazı sıcaklığının arttığını, karbon monoksit (CO) emisyonun azaldığını, is emisyonunu azaldığını ve azot oksit (NOx) emisyonunun arttığını bildirmişlerdir. Ayrıca hava/yakıt (H/Y) oranının etkisinin de yanma üzerindeki etkilerini araştırmak için değişik $\mathrm{H} / \mathrm{Y}$ oranlarında deneylerini tekrarlamışlardır. H/Y oranın artması ile birlikte silindir içi basınç değerlerinin de arttığını bildirmişlerdir.

Asetilen gazının yanma sonu sıcaklığının yüksek olması nedeniyle metal sanayinde kesme ve kaynak işleri kullanımında tercih edilmektedir [6]. Asetilen gazı hazır tüplerden satın alınarak kullanabileceği gibi karpit kazanları ile de elde edilebilmektedir. Asetilen gazı karpit kazanlarında hızlıca üretilebildiği ve hemen kullanıma hazır hale geldiği için birçok sanayi kuruluşunca bu gaz temin süreci tercih edilmektedir.

Asetilenin alev gücü $43 \mathrm{kw} / \mathrm{cm}^{2}$ ve alev sıcaklığ $3200^{\circ} \mathrm{C}^{\prime}$ dir. Diğer gazlar arsında alev sıcaklı̆̆ 1 bakımında en yüksek sıcaklığa sahip gaz türüdür [14]. Ayrıca asetilen renksiz, boğucu, sarımsak kokusuna benzer kokuda, oldukça parlayıc1, zehirsiz, çözünmüş bir gazdır. Asetilen gerek tüpte olsun gerekse karpit kazanlarında karpitin suyla temasından elde edilir. Karpitin tane büyüklügüne bağl1 olarak $1 \mathrm{~kg}$ 'dan elde edilecek asetilen miktarı değişmektedir. Tanelerin büyüklügüne göre $0,5 \mathrm{~kg}$ ile 0,3 kg arasındaki değerler aralığında karpit üretimi gerçekleşebilmektedir. Şekil 1'de piyasada satılan karpit büyüklüklerinde su ile karıştırılması sonucunda ortaya çıkan ürünleri göstermektedir [15].

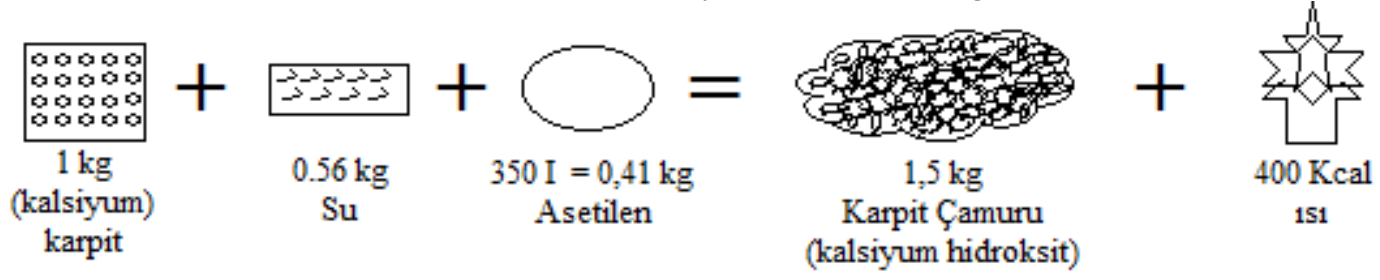

Şekil 1. Karpitin suyla karıştırılması sonucu ortaya çıkan ürünler [11]

İlhak ve ark. [10] dört silindirli, dört zamanlı benzinli bir motorda $500 \mathrm{~g} / \mathrm{h}$ ve $1000 \mathrm{~g} / \mathrm{h}$ asetilen gazı ilavesinin motor performansına ve egzoz emisyonlarına etkisini incelemişlerdir. Benzine $500 \mathrm{~g} / \mathrm{h}$ asetilen ilavesi ile birlikte \%50 motor yükünde silindir içi basıncın arttığını, $1000 \mathrm{~g} /$ asetilen gazı ilavesi ile yanmanın uzayarak maksimum silindir içi basıncının azalttığını belirtmiş̧lerdir. Tam yük durumunda ise asetilen gazı ilavesinin silindir içi basıncında azalmalara neden olduğunu bildirmişlerdir. Bunun yanında asetilen gazı ilavesi ile birlikte egzoz gazı sıcaklığının arttığını, düşük motor güçlerinde termal verimin düşük ve yakıt tüketiminin fazla yüksek güçlerde ise termal verimin yüksek ve yakıt tüketiminin az olduğunu belirtmişlerdir. Emisyonlar açısından bakıldığında ise hidrokarbon (HC) emisyonlarının azaldığını NOx emisyonlarının arttığını belirtmektedirler. 
Vural ve Özer [11] yaptıkları deneysel çalışmalarında, buji ateşlemeli, 4 zamanlı tek silindirli bir motorda 1600-3200 d/dak motor hızları arasında tam gaz konumunda benzine kütlece $\% 20$ ve $\% 30$ oranında asetilen gazı ilavesinin egzoz emisyonlarına etkilerini incelemişlerdir. Yaptıkları çalışmada egzoz gazı sıcaklığı ile $\mathrm{CO}, \mathrm{CO} 2$, NOx emisyonlarında benzinle çalışmaya göre azalma meydana getirdiğini gözlemlemişlerdir. Benzine $\% 20$ ve $\% 30$ oranlarında ilave edilen asetilenin yanmayı kötüleştirdiğini bu nedenle gazın emme manifoltundan değil de ikinci bir enjeksiyon ile verilmesinin daha güvenli ve verimli olacağını bildirmişlerdir.

Lakshmanan ve Nagarajan [12] tek silindirli, 4 zamanlı direk püskürtmeli dizel bir motorda asetilen gazı ilavesinin motor performansına ve egzoz emisyonlarına etkisini incelemişlerdir. Dizel yakıtının pilot yakıt olarak gönderildiği çalışmada asetilen kullanımı ile termal verimin düştüğünü, is, $\mathrm{HC}$ ve CO emisyonlarında azalma meydana geldiğini NOx emisyonlarının ise arttı̆̆ını bildirmişlerdir.

Lakshmanan ve Nagarajan [13] dizel yakıtına $110 \mathrm{~g} / \mathrm{h}, 180 \mathrm{~g} / \mathrm{h}$ ve $240 \mathrm{~g} / \mathrm{h}$ asetilen gazı ilave ederek değişik oranlarda EGR uygulamasının egzoz emisyonlarına ve motor performansa etkilerini incelemişlerdir. Dizel yakıtına ilave edilen asetilen gazının NOx, CO ve HC emisyonlarının azalmasına, is emisyonlarının ise makul bir derecede artmasına neden olduğunu EGR uygulamasının ise emisyonları bir miktar iyileştirdiğini tespit etmişlerdir.

Yapılan çalışmalar asetilen gazının içten yanmalı motorlarda kullanılabildiğini göstermektedir. Asetilen gazının yerli kaynaklarla üretiliyor olması ve yüksek 1sıl değere sahip olması içten yanmalı motorlarda alternatif bir yakıt olarak kullanılabileceğini göstermektedir. Bu çalışmada da tek silindirli, dört zamanlı dizel bir motora sahip ev tipi jeneratörde dizel yakıtına biyodizel ilavesi ve üzerine asetilen gazı ilave edilmesinin yakıt tüketim değerine ve emisyonlara etkileri incelenmiştir. Bu amaçla dizel bir jeneratöre bağlanan projektörler vasıtasıyla $1000 \mathrm{~W}, 2000 \mathrm{~W}, 3000 \mathrm{~W}$ ve $4000 \mathrm{~W}$ güç çekecek şekilde projektör lambaları ile yüklenerek çalıştırılmıştır. Çalışma sırasında tüketilen dizel+biyodizel yakıtların tüketim miktarları ile egzoz emisyonları kayıt altına alınmış ve daha sonra irdelenmiştir.

\section{Materyal ve Metot}

Alternatif yakıt çalışmalarında yakıtların belli başlı bazı özellikleri üzerine kıyaslamalar yapılarak yorumlamak mümkündür. Tablo 1'de motorlarda kullanılan asetilen, dizel, biyodizel ve dizel+biyodizel yakıtların özellikleri verilmektedir. Görüldüğü gibi asetilen gazının ısıl değeri ve yanma sonu sıcaklığı dizel ve dizel+biyodizel yakıtlara göre oldukça yüksektir. Bu durum içten yanmalı motorlarda alternatif yakıt olarak kullanılabileceğinin bir göstergesi olarak görülebilir. Ayrıca H/Y oranı da benzin ve dizel yakıtlarına yakındır. Deneyde kullanılan asetilen gazı Habaş firmasından dizel yakıt ise OPET firmasından temin edilmiştir. Biyodizel ise atık yağlardan imal edilmiştir. Elde edilen biyodizel ve dizel+biyodizel yakıtlarının fiziksel ve kimyasal özellikleri Gazi Üniversitesi laboratuvarlarında ölçülmüştür.

Tablo 1. Yakıtların fiziksel ve kimyasal özellikleri

\begin{tabular}{|c|c|c|c|c|}
\hline Özellikler & Asetilen $^{[13,17,18]}$ & Dizel Yakıtı $^{[16]}$ & Biyodizel & Biyodizel+Dizel $^{*}$ \\
\hline Formül & $\mathrm{C}_{2} \mathrm{H}_{2}$ & $\mathrm{C}_{8}-\mathrm{C}_{20}$ & $\mathrm{C}_{12}-\mathrm{C}_{22}$ & - \\
\hline Yoğunluk ${ }^{\mathrm{a}}$ & 1,092 & 840 & 882 & 849 \\
\hline Kendi Kendine Tutuşma Sıcaklığı & 578 & 527 & - & - \\
\hline Stikiyometrik oran $(\mathrm{kg} / \mathrm{kg})$ & 13,2 & 14,5 & - & - \\
\hline Yanma Limitleri (Hacimsel Olarak \%) & $2,5-81$ & $0,6-5,5$ & 4,2 & 3,4 \\
\hline Yanma Sonu Sıcaklığı (K) & 2500 & 2200 & - & - \\
\hline Isıl Değeri (MJ/kg) & 48,225 & 42,500 & 37,388 & 39,6 \\
\hline Alt Isıl Değeri (MJ/kg) & 33,96 & 36,6 & 33,88 & 34,3 \\
\hline
\end{tabular}

a: $\left(1,01325\right.$ bar ve $\left.293 \mathrm{~K}\left(\mathrm{~kg} / \mathrm{m}^{3}\right)\right)$

\subsection{Deney Düzeneği ve Yöntem}

Motor deneyleri içten yanmalı, tek silindirli, dört zamanlı bir dizel Genpower marka jeneratörün GDG 7000 modelinde gerçekleştirilmiş̧ir. Dizel motor direk enjeksiyon sistemine sahiptir. Yakıt olarak ise \%50 biyodizel/\%50 dizel yakıt ve asetilen gazı kullanılmıştır. Deney düzeneğinin şematik resmi Şekil 1 'de verilmektedir. Deneylerde kullanılan yakıtların teknik özellikleri Tablo 1'de jeneratörün teknik özellikleri ise Tablo 2'de verilmektedir. 
Tablo 2. Deney düzeneğinin teknik özellikleri

\begin{tabular}{lc}
\hline & Motor \\
\hline Model & 186 FAG \\
Tip & Hava Soğutmalı- 4 Zamanlı \\
Silindir Hacmi & $418 \mathrm{~cm}^{3}$ \\
Maksimum Çıkış gücü & $5.7 \mathrm{~kW}$ \\
Sıkıştırma Oranı & $19: 1$ \\
Çalışırma Şekli & Marşlı \\
\hline \multicolumn{2}{c}{ Jeneratör } \\
\hline Maksimum Çıkış Gücü & $7 \mathrm{kVA}$ \\
Sürekli Çalışma Gücü & $6 \mathrm{kVA}$ \\
Frekans & $50 \mathrm{~Hz}$ \\
\hline
\end{tabular}

Deney sirasında asetilen gazı temininde RAL 1018 tipi, TSE 11169 normlarına uygun bir asetilen tüpü kullanılmıştır. Asetilen (gaz yakıt) yüksek basınçlı (15 bar) bir tüpten basınç regülatörü yardımı ile 1,5 bara düşürülerek ve sırası ile emniyet valfi, gaz debimetresi, sulu güvenlik, ikinci bir emniyet valfi ile vanadan geçirilerek motorun emme manifolduna verilmiştir. Egzoz gaz sicaklık ölçümleri K tipi termokuplla gerçekleştirilmiştir. Egzoz emisyonlarının ölçülmesinde Tablo 3'de ölçüm aralıkları ve hassasiyetleri verilen Mobydic 5000 marka gaz analiz cihazı kullanılmıştır. Her bir deney verisi elde etmek için deneyler üçer kez tekrarlanmıştır. Deney düzeneğinin şematik görünümü Şekil 2'de verilmektedir.

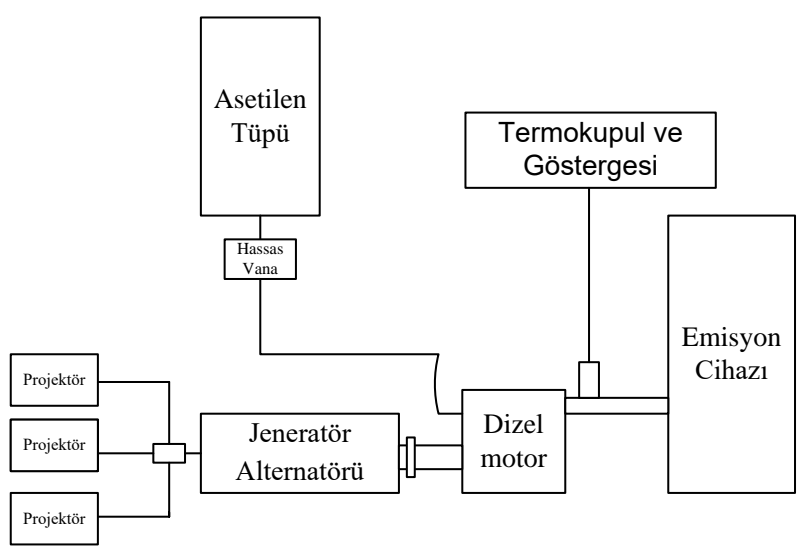

Şekil 2. Deney düzeneğinin şematik görünümü

Tablo 3. Emisyon cihazının özellikleri ve ölçüm aralıkları

\begin{tabular}{lc}
\multicolumn{2}{c}{ MOBYDIC 5000 gaz analiz cihaz } \\
\hline $\mathrm{CO} \%$ Vol & $0-10$ \\
$\mathrm{HCppmVol}$ & $0-2000$ \\
$\mathrm{O}_{2} \% \mathrm{Vol}$ & $0-21$ \\
$\mathrm{NOxppm}$ & $0-5000$ \\
$\mathrm{n} \%$ & $0-100$ \\
$\mathrm{k} 1 / \mathrm{m}$ & $0-20$ \\
\hline
\end{tabular}

Dizel yakıtının içerisine hacimce $\% 50$ oranında biyodizel ilave edilerek yakıt karışımı oluşturulmuştur. Bu karışımlardan sadece dizel yakıtına D100, biyodizel ile oluşturulun karışıma da D50B50 kısaltması kullanılmıştır. Ayrıca kütlece \%10 asetilen ilavesi ile oluşturulan yakıt karışımlarına DA10, DB10 ve \%20 asetilen gazı ile oluşturulana D20, DB20 isimleri verilmiştir. Motor deneyleri sabit motor hızında (3000 d/dak) gerçekleştirilmiştir. Bu amaçla jeneratör öncelikle D100, D50B50 yakıtı ile $1000 \mathrm{~W}, 2000 \mathrm{~W}, 3000 \mathrm{~W}, 4000 \mathrm{~W}$, güç üretecek şekilde yüklenmiş̧ir. Bu aşamada emisyon değerleri ve yakıt tüketim değerleri kayıt altına alınmıştır. Yapılan bu ön çalışmaların sonrasında ise motorun saatlik yakıt tüketim değerleri hesaplanmıştır. Hesaplanan bu değerler baz alınarak emme manifoltundan kütlece $\% 10$ ve $\% 20$ oranında asetilen gazı ilave edilmiştir. İlave edilen asetilen gazı kütlesel bir akış metre üzerinden $\mathrm{kg} / \mathrm{h}$ değeri ile baz alınarak ilave edilmiştir. Tüm bu aşamalarda motorun kararlı hale geçmesi beklenmiş ve dizel+biyodizel+asetilen yakıt ile çalışan motorun emisyon değerleri ile yakıt tüketim değerleri tekrar ölçülmüştür. Çünkü jeneratörün sisteminde var olan elektronik regülatör devresi 
yakıt tüketimini ayarlayarak motor devrini sabit bir devir altında tutarak çalışmaktadır. Bu nedenle her asetilen gazı ilavesinde motor dizel yakıt miktarını motor devrini sabit tutacak şekilde otomatik olarak kısmakta yâda artırmaktadır. Bu durum yapılan ölçümlerle tespit edilmiş ve sonuçlar bölümünde başlı başına irdelenmektedir. Her deney aşamasında motorun kararlı duruma geçtiği çalışma sıcaklığından sonra yakıt tüketim verileri, egzoz gazı sıcaklığı (EGS),CO, HC, is ve NOx emisyon verileri kayıt altına alınarak değerlendirilmiştir.

\section{Bulgular}

\subsection{Yakıt Tüketimi}

Şekil 3'de motor yükünün yakıt tüketim değerine etkisi verilmektedir. Motor yükünün artmasına bağl1 olarak yakıt tüketim değerinin artması beklenilen bir durumdur. Bunu daha fazla güç üretmek için silindir içerisine gönderilen yakıt miktarının artırılmasının önceliği olarak görmek gerekir. Bu nedenle en yüksek yakıt tüketim değerleri $4000 \mathrm{~W}$ motor yükü değerlerinde görülmektedir. Tüm yakıt karışımlarında DB yakıt karışımı en yüksek yakıt tüketimine sahiptir. Manifolttan asetilen gazı ilavesi ile birlikte dizel+biyodizel yakıt tüketim değerinde düşüş görülmektedir. $\mathrm{Bu}$ durum silindir içerisine alınan toplam enerji miktarının ve yanmanın verimi ile doğrudan ilişkilidir. Elde edilen sonuçlar göstermektedir ki, ilave edilen asetilen gazı kadar dizel+biyodizel yakıtlardan tasarruf sağlanamamıştır. Fakat tüm motor yüklerinde DB yakıt karışımına asetilen gazı ilavesi ile birlikte daha fazla bir dizel+biyodizel yakıt tasarrufu sağlanmıştır. $\mathrm{Bu}$ durum DB yakıt karışımının oksijence zengin olmasından kaynaklandığı düşünülmektedir. Oksijence zengin yakıtlar silindir içerisinde kısmen daha iyi bir yanma performansı sağlamakta ve yanmayı iyileştirmektedir [19].

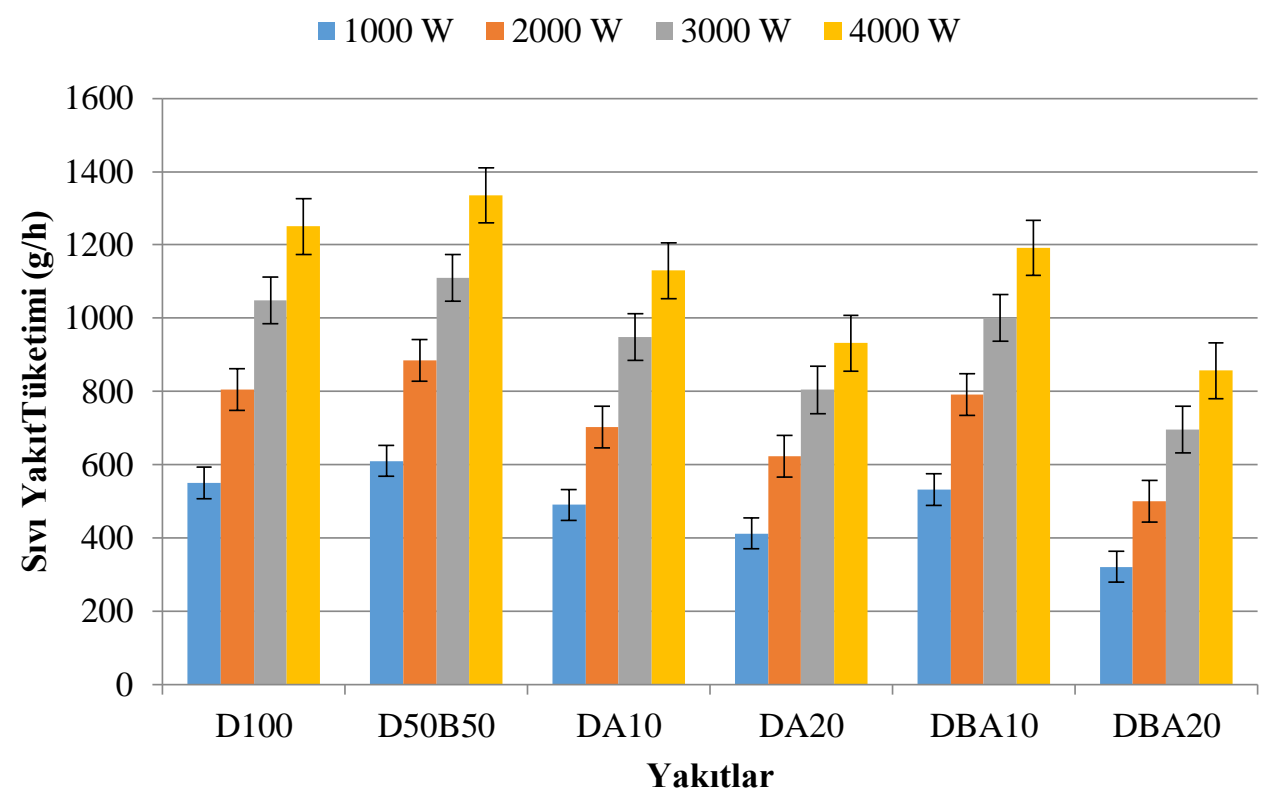

Şekil 2. Yakıt tüketim değeri (3000 d/dak)

Şekil 2'de dizel+biyodizel yakıt tüketimi verilmektedir. Bunun yanında dizel+biyodizel yakıt ile birlikte Tablo 4'de belirtilen oranlarda akış metre üzerinden hassas bir şekilde ayarlanarak asetilen gazı ilave edilmiştir. Tablo 5'de ise ilave edilen asetilen gazı sonrasında motordaki dizel+biyodizel yakıtların azalmasındaki miktar ifade edilmektedir. 
Tablo 4. İlave edilen asetilen gazı miktarı

\begin{tabular}{|c|c|c|c|c|}
\hline & \multicolumn{2}{|c|}{ Kütlece $\% 10$ Asetilen $(\mathrm{g} / \mathrm{h})$} & \multicolumn{2}{|c|}{ Kütlece $\% 20$ Asetilen $(\mathrm{g} / \mathrm{h})$} \\
\hline & $\mathrm{D}$ & DB & $\mathrm{D}$ & DB \\
\hline $1000 \mathrm{~W}$ & 55 & 61 & 110 & 122 \\
\hline $2000 \mathrm{~W}$ & 81 & 89 & 161 & 177 \\
\hline $3000 \mathrm{~W}$ & 105 & 111 & 210 & 222 \\
\hline $4000 \mathrm{~W}$ & 125 & 134 & 250 & 267 \\
\hline
\end{tabular}

Tablo 5. Asetilen gazı ilavesi sonrasında azalan dizel+biyodizel yakıt miktarı

\begin{tabular}{|c|c|c|c|c|}
\hline & \multicolumn{2}{|c|}{ Kütlece \%10 Asetilen $(\mathrm{g} / \mathrm{h})$} & \multicolumn{2}{c|}{ Kütlece \%20 Asetilen $(\mathrm{g} / \mathrm{h})$} \\
\hline & D100 & D50B50 & D100 & D50B50 \\
\hline $1000 \mathrm{~W}$ & 60 & 78 & 138 & 169 \\
\hline $2000 \mathrm{~W}$ & 103 & 94 & 182 & 201 \\
\hline $3000 \mathrm{~W}$ & 99 & 109 & 244 & 253 \\
\hline $4000 \mathrm{~W}$ & 120 & 143 & 318 & 273 \\
\hline
\end{tabular}

Genel olarak bakıldığında asetilen gazı ilavelerinde dizel+biyodizel yakıt miktarlarında ilave edilen asetilen gazından daha fazla miktarda azalma görülmektedir. Asetilen gazının kütlesel olarak D100 ve D50B50 yakıt karışımından daha fazla 1sıl değere sahiptir. Bu nedenle 1sıl değerce ilave edilen miktar kadar azalma olması beklenilmesi bir durumdur. Fakat elde edilen bu sonuçlar göstermektedir $\mathrm{ki}$, asetilen gazı tam manasıyla silindir içerisinde yanamamaktadır.

Şekil 4'de asetilen gazı ilavesinin enerji tüketim değerine etkisi verilmektedir. Gazla yapılan çalışmalarda enerji tüketim değeri ile daha iyi bir anlam çıkartılabileceğini belirten birçok çalışma mevcuttur [20]. Görüldügü gibi D50B50 yakıt karışımına asetilen gazı ilavesi ile birlikte daha az bir enerji talebi olmuştur. Daha öncede bahsedildiği gibi asetilen gazı biyodizel karışımları ile daha iyi bir yanma performansı sergilemiştir. Böylelikle aynı motor gücünün elde edilmesi için diğer yakıtlara göre daha az bir enerjiye ihtiyaç duyulmuştur. En ideal enerji tüketim değeri DBA20 yakıt karışımı ile 11,7 $\mathrm{MJ} / \mathrm{kWh}$ değeri ile $4000 \mathrm{~W}$ motor gücünde elde edilmiştir.

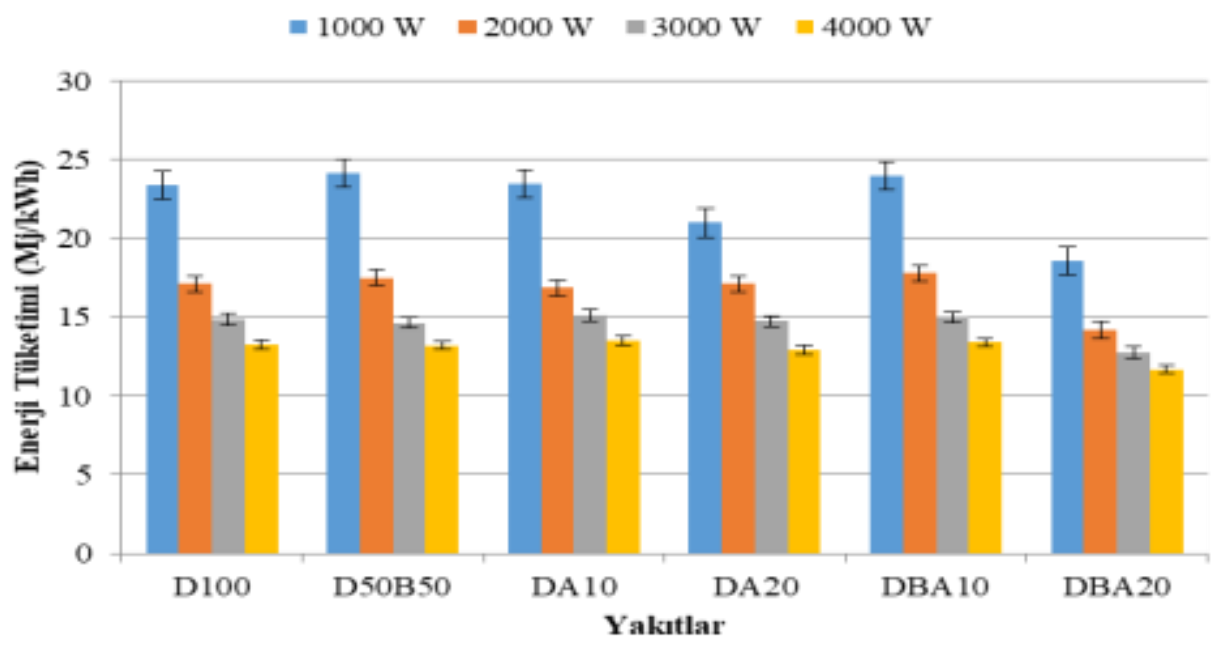

Şekil 4. Enerji tüketimine etkisi(3000 d/dak)

Şekil 5'de asetilen gazı ilavesinin egzoz gazı sıcaklığına etkisi verilmektedir. Tüm yakıt karışımlarında motor gücünün artması ile egzoz gazı sıcaklığı artış göstermektedir. Ayrıca asetilen gazının ilavesi ile birlikte egzoz gazı sıcaklığında da bir artış söz konusudur. Asetilen gazı ilavesinin egzoz gazı sıcaklığındaki artışta etkin olduğu açıkça bellidir. Bu durum asetilen gazının ısıl değerinin yüksek olması ve tutuşma gecikmesine bağlıdır. Ayrıca asetilenin bir kısmının silindir içerisinde tam manasıyla yanamadığı ve egzoz gazı üzerinden atıldığı düşünülmektedir. D50B50 yakıt karışımına eklenen asetilen gazı egzoz gazı sıcaklığını daha fazla artırmıştır. Bu durumunda D50B50 yakıtının içerisindeki oksijenin varlığı ile açıklanabilir. Okjince zengin yakıtların kısmen yanmayı iyileştirerek 
silindir içerisinde yanma sonu sıcaklığını artırdığı bilinmektedir. Asetilen gazı ilavesi ile birlikte egzoz gazı sıcaklığının artması ileride belki bu enerjiden yararlı elektrik üretiminde etkili olabilecek bir avantaj olarakta görülmelidir. Çünkü gelişen teknolojik araçlar ile egzoz gazının ısısından elektrik enerjisi üreten sistemlerin tasarımı giderek artış göstermektedir [21]. Gerek motorun soğutma suyundan gerekse egzozundan bazen 1s1 enerjisi üretimi bazen de elektrik enerjisi üretimi ile atılan enerjinin geri kazanılması planlanmaktadır [22]. Yapılacak bu tür tertibatlar ile egzoz sistemine kurulacak bir termoelektrik jeneratör ile asetilen gazı kullanımındaki egzoz gazı sıcaklığı yararlı bir iş için kullanılabilir duruma getirilebilir.

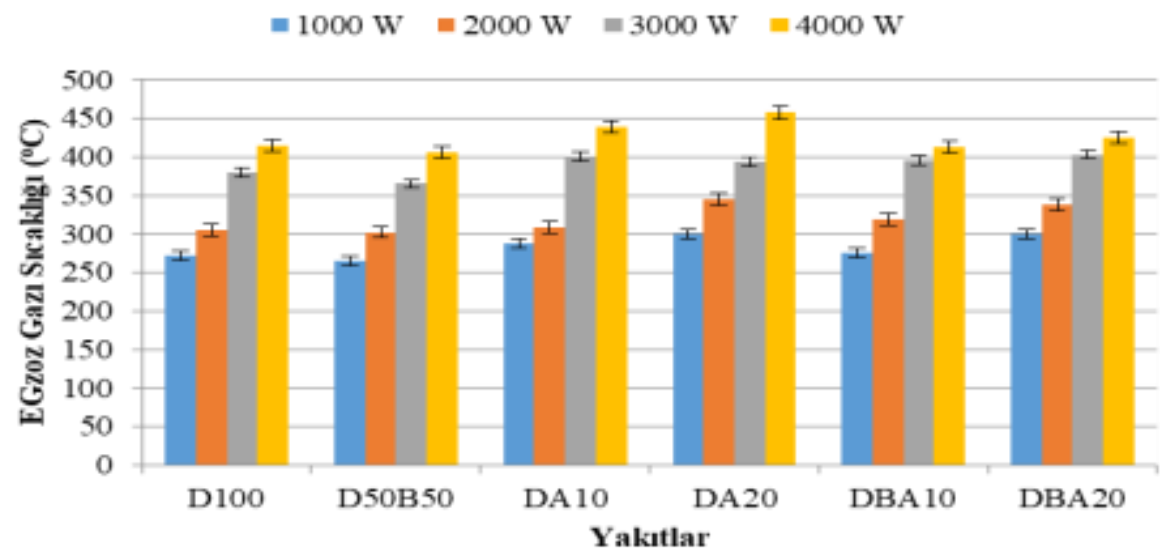

Şekil 5. Asetilen gazı ilavesinin egzoz gazı sıcaklığına etkisi(3000 d/dak)

\subsection{Egzoz Emisyonları}

Şekil 6'da dizel yakıtına asetilen gazı ilavesinin NOx emisyonlarına etkisi verilmektedir. Genel olarak azot $(\mathrm{N})$ atomunun yanması sonucu oluşan emisyonlara NOx emisyonları denilmektedir. NOx emisyonları yüksek sıcaklıktan oluşmaktadır ve dizel motorlarında sorun haline gelen önemli bir emisyondur [23]. Yapılan çalışmanın sonuçları incelendiğinde tüm karışım oranlarında yükün artması ile birlikte NOx emisyonlarının arttığı göstermektedir. Özellikle D50B50 yakıt karışımı ile NOx emisyonlarının artması litetürdeki benzer çalışmalarında ifade ettiği gibi içeriğindeki oksijen miktarı ve setan sayısı ile açıklanmaktadır. Biyodizel karışımlarındaki yüksek setan sayısı ve oksijen miktarı yakıtın birikerek aniden yanmasını doğurmaktadır. Bu durumda NOx emisyonlarını artırmaktadır. Bunun yanında kütlece ilave edilen asetilen gazı ile birlikte yüksek oranda NOx emisyonlarının arttığı görülmüştür. Bu durum silindir içerisindeki ani yanma, asetilengazının yüksek 1sıl değeri ve asetilen gazının egzozda yanmaya devam etmesi ile açıklanabilir. Yapılan çalışmanın sonucu literatürdeki [24, 25] çalışma ile benzerlik göstermektedir.

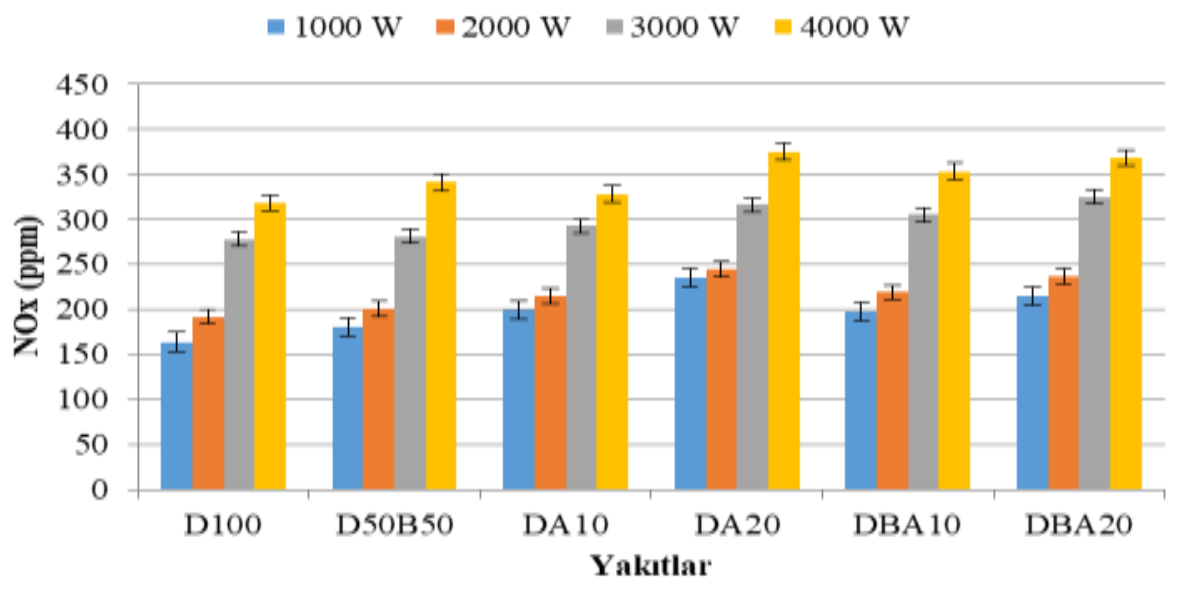

Şekil 6.Asetilen gazı ilavesinin egzoz NOx emisyonlarına etkisi (3000 d/dak). 
Şekil 7'de dizel yakıtına asetilen ilavesinin CO emisyonlarına etkisi verilmektedir. CO emisyonu eksik yanmaını bir sonucu olarak ortaya çıkmaktadır. CO emisyonları açısından dizel motorlar aslında yok denecek kadar az emisyon üretmektedir. Çünkü dizel motorlarda yüksek oranda hava fazlalığ oksijen bulunmaktadır. Öbür taraftan düşük yüklerde $\mathrm{CO}$ emisyonu yüksekken yükün artması ile birlikte bir miktar azalmakta ve yük miktarı da da arttıkça başlangıç yükünün durumuna göre $\mathrm{CO}$ emisyonlarında aşırı bir artış görülmektedir. Bu durumu ifade etmek için dizel motorların çalışma prensibine bakmak gerekir. Tek silindirli, mekanik enjektörlü direk dizel motorlarında motor devri silndir içerisine püskürtülen yakıt miktarı ile ayarlanmaktadır. Düşük motor yüklerinde az miktarda püskürtülen yakıt çok fakir koşulların oluşması ile birlikte tam olarak yanamaz ve soğuk bölgelerde tutuşma gerçekleşmediği için $\mathrm{CO}$ emisyonları oluşur. Fakat yükün artması ile birlikte artan yakıt miktarı daha ideal bir yakıt/hava karışımı meydana getirerek silindir içerisinde daha ideal bir karışımı oluşturur. Böylelikle CO emisyonları düşer. Fakat yakıt miktarının dahada artırılması ideal yakıt/hava karışımını bozarak tekrar ideal karışımı bozar ve CO emisyonlarında artış tekrar artar. Genel olarak D100 yakıtına göre D50B50 yakıtında CO emisyonları düşüş göstermiştir. Bu durumun biyodizelin içerisindeki oksijen varlığ 1 ve toplam karbon atomu sayısının azlığı ile açıklamak mümkündür. Öbür taraftan bu yakıtlara ilave edilen asetilen gazı ile birlikte $\mathrm{CO}$ emisyonlarında azalma devam etmiştir. Burada asetilen gazının 1sıl değerinin yüksek olmasının ve yanma sonu sıcaklığında artış ile açıklamak mümkündür. Asetilen gazı kısmen silindir içerisindeki yanmanın artmasına ve $\mathrm{CO}$ emisyonlarının azalmasına neden olmuştur. Çalışmanın sonuçları literürdeki benzerlik göstermektedir [26].

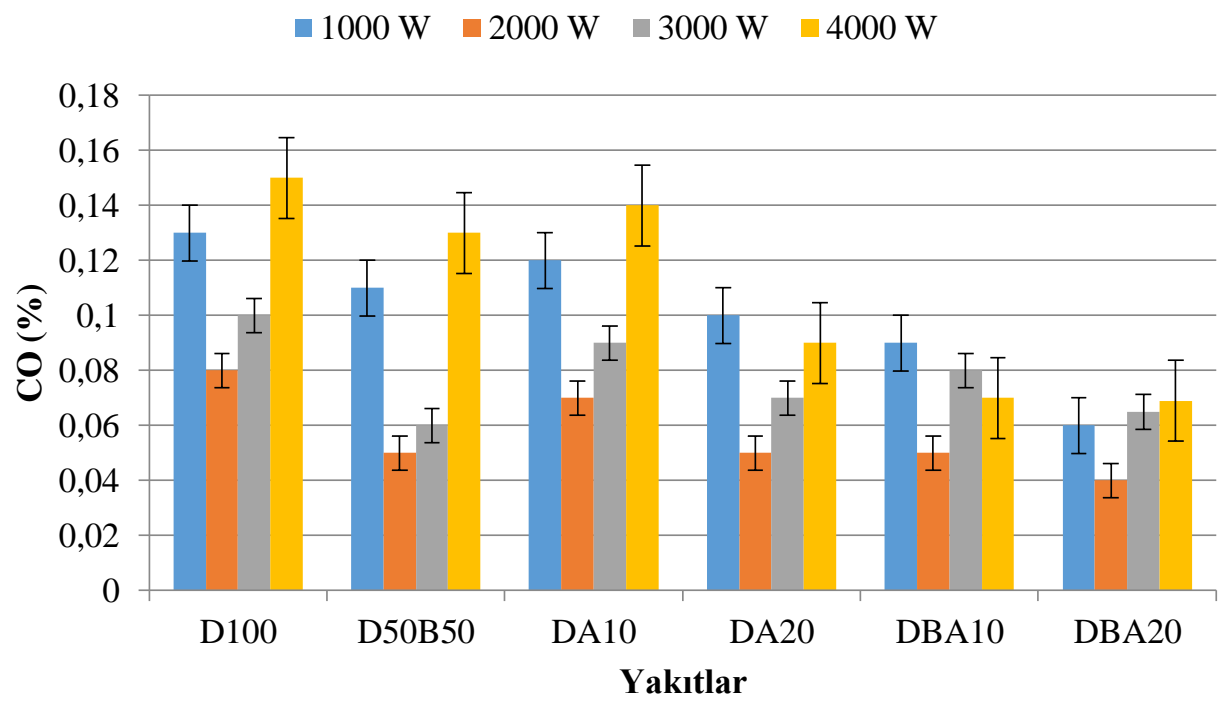

Şekil 7. Asetilen gazı ilavesinin CO emisyonlarına etkisi(3000 d/dak).

Şekil 8'de dizel yakıtına asetilen ilavesinin is emisyonlarına etkisi verilmektedir. İs emisyonları dizel+biyodizel yakıtlarının egzoz gazı içerisinde yanmadan atılması ile oluşmaktadır. Özellikle dizel motorlarında önemli bir is emisyonu olarak ortaya çıkmaktadır. Motor yükünün artmasına paralel olarak is emisyonlarının artması dizel motorlarında beklenilen bir durumdur. Çünkü silindir içerisine eklenen yakıt miktarı arttığı için toplam is emisyonları artış göstermektedir. Biyodizel kullanımı ile birlikte is emisyonlarında azalma görülmektedir. Bu durum biyodizel kullanımı ile birlikte beklenen bir durumdur. Bunun yanında yakıtlara asetilen gazı ilavesi ile birlikte is emisyonlarında daha fazla bir azalma görülmektedir. Bu durum toplam karbon sayısındaki azalma ve yanma sonu sıcaklığının kısmen artıyor olması ile açıklanabilir. Elde edilen veriler literatürdeki [27] çalışma ile benzerlik göstermektedir. 


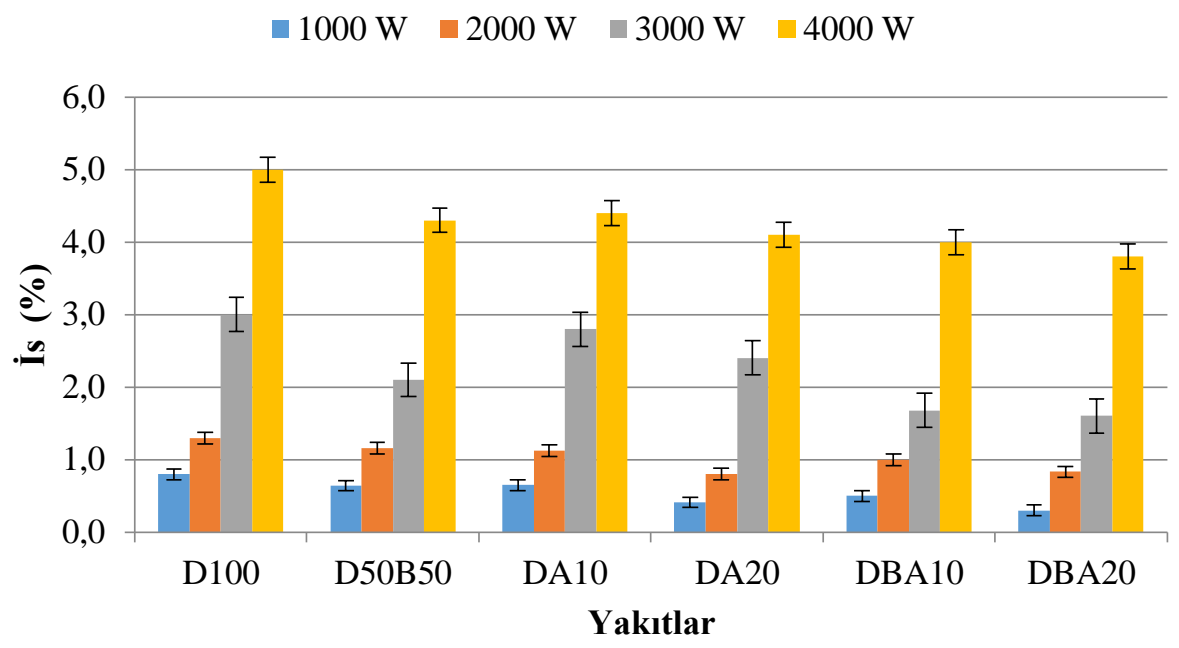

Şekil 8. Asetilen gazı ilavesinin is emisyonlarına etkisi (3000 d/dak)

Şekil 9'da dizel+biyodizel yakıt karışımlarına asetilen gazı ilavesinin HC emisyonlarına etkisi verilmektedir. HC emisyonları silindir içerisinde kısmen yakıt zerreciklerinin yanmaması sonucunda egzozdan atılan yakıtlar olarak tanımlanmaktadır [28]. Dizel motorlar hava fazlalığı ile çalıştığı için genelde çok yüksek değerlerin çıkması beklenen bir durum değildir. Temel olarak silindir içerisindeki yanmanın ksımen yada tamamen kötüleşmesi ile $\mathrm{HC}$ emisyonları artış gösterebilir. Motor yükünün artması ile birlikte tüm yakıt karışımlarında $\mathrm{HC}$ emisyonlarında artış görülmüşsür. Bunun yanında dizel yakıtına biyodizel ilavesi ile birlikte ise $\mathrm{HC}$ emisyonlarında genel olarak bir azalış söz konusudur. $\mathrm{Bu}$ durum asetilen gazı ilavesi ile birlikteyse artış göstermektedir. Asetilen gazının yüksek yanma sonu sıcaklığı ve 1 sıl değeri silindir içerisinde kısmen yanmayı iyileştirmektedir. Bunun yanında gaz ilavesi ile birlikte dizel+biyodizel fazdaki yakıtların kullanılmasında azalışda görülmektedir. $\mathrm{Bu}$ nedenle asetilen gazının silindir içerisinde kısmen yanmayı iyileştirdiği ve $\mathrm{HC}$ emisyonlarının oluşmasını azalttığı düşünülmektedir. Literatürdeki benzer çalışmalar [29] ile de benzerlik göstermektedir.

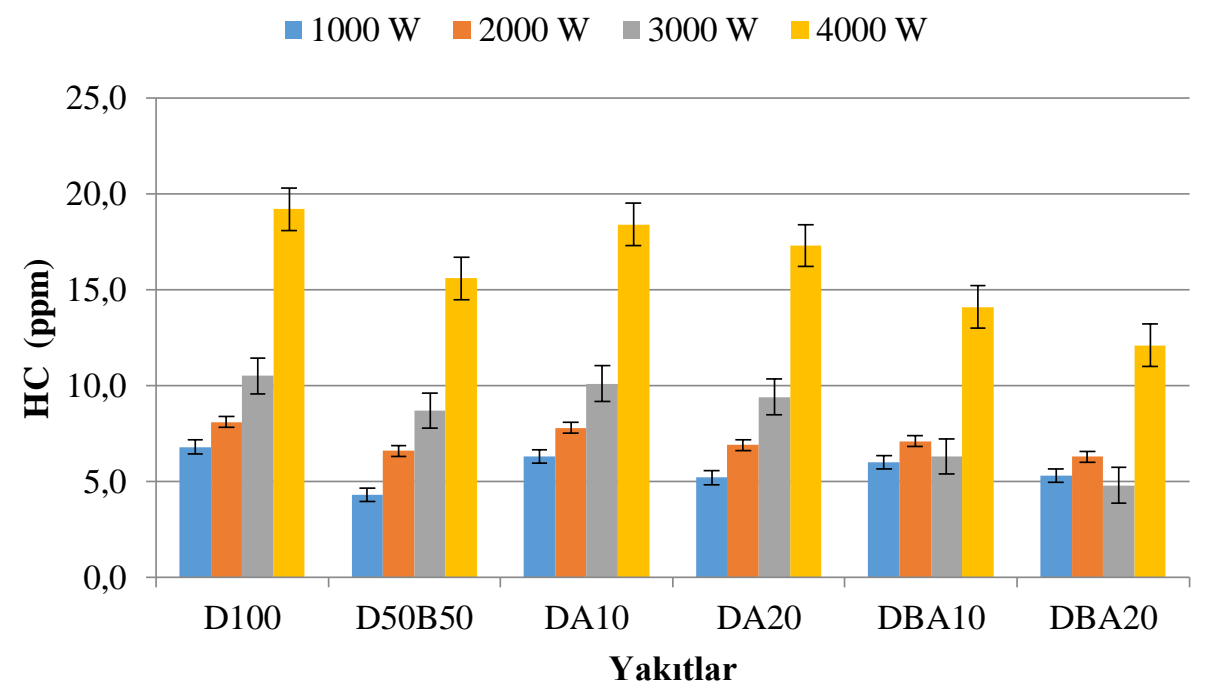

Şekil 9. Asetilen gazı ilavesinin HC emisyonlarına etkisi (3000 d/dak)

\section{Sonuç ve Öneriler}

Dizel yakıtına ve dizel+biyodizel yakıt karışımına asetilen gazı ilavesinin mümkün olduğu ve dizel bir motora sahip jeneratörde asetilen gazının kütlece $\% 20$ oranında eklenebileceği görülmüştür. Yapılan çalışmanın sonucunda asetilen gazı ilavesinin yakıt tüketimini arttırdığı görülmüştür. Bu durum her ne kadar yakıt maliyetlerini artırıyor gibi görünse de biyodizel kullanımı ile birlikte maliyetler çok aşağılara 
kadar inmektedir. Bu nedenle biyodizel yakıtı gibi asetilen gazı da milli kaynaklarla üretilebilecek kolay ve kullanışlı bir yakıt olma özelliği ile ön plana çıkabilecek bir alternatif yakıt türevidir. Asetilen gazı ilavesi ile birlikte her ne kadar NOx emisyonları artış göstermiş olsa da $\mathrm{HC}, \mathrm{CO}$ ve is emisyonlarında kayda değer bir iyileşme görülmüştür. Bu nedenle asetilen gazı alternatif yakıt olma yolunda önemli bir kaynak olarak göz önünde bulundurulmalıdır. Bunun yanında yanma performansını iyileştirecek bazı düzenlemeler ile yakıt tüketim değerleri ve motor parçalarına olan etkileri yönünden de incelenmelidir.

\section{Yazarların Katkısı}

Yazarlar bu araştırma makalesine eşit katkı sunmuşlardır.

\section{Çıkar Çatışması Beyanı}

Yazarlar arasında herhangi bir çıkar çatışması bulunmamaktadır.

\section{Araştırma ve Yayın Etiği Beyanı}

Yapılan çalışmada araştırma ve yayın etiğine uyulmuştur.

\section{Kaynaklar}

[1] Bayraç N., Çelikday F., Çildir M. 2018. Küreselleşme Sürecinde Sürdürülebilir Enerji Politikaları. Ekin Yayınevi, Bursa.

[2] Koç E., Şenel M.C. 2013. Türkiye Enerji Potansiyeli ve Yatırım-Üretim Maliyet Analizi. Termodinamik Dergisi, 245: 72-84.

[3] Kaya K., Koç E. 2015. Enerji Üretim Santralleri Maliyetleri. Mühendis ve Makine, 56 (600): 61 68.

[4] Zhen X., Wang Y., Liu D. 2020. Bio-butanol as a new generation of clean alternative fuel for SI (spark ignition) and CI (compression ignition) engines. Renewable Energy, 147 (1): 2494-2521.

[5] Choudhary K.D., Nayyar A., Dasgupta M.S. 2018. Effect of compression ratio on combustion and emission characteristics of C.I. Engine operated with acetylene in conjunction with diesel fuel. Fuel, 214: 489-496.

[6] Milli Eğitim Bakanlığı, MEGEP, 2010. Temel Kaynak 1. http://megep.meb.gov.tr/mte_program_modul/moduller_pdf/Temel\%20Kaynak\%201.pdf (Erişim tarihi: 10.06.2019).

[7] İlhak M.İ., Doğan R., Akansu S.O., Kahraman N. 2020. Experimental study on an SI engine fueled by gasoline, ethanol and acetylene at partial loads. Fuel, 261: 116148.

[8] Raman R., Kumar N. 2019. The utilization of n-butanol/diesel blends in Acetylene Dual Fuel Engine. Energy Reports, 5: 1030-1040.

[9] İlhak İ.M., Tangöz S., Akansu O.S, Kahraman N. 2019. An experimental investigation of theuse of gasoline-acetylene mixtures at different excessairratios in an SI engine. Energy, 175: 434-444.

[10] İlhak İ.M., Akansu O.S., Kahraman N., Ünalan S. 2018. Experimental study on an SI engine fuelled by gasoline/acetylene mixtures, Energy, 151: 707-714.

[11] Vural E., Özer S. 2014. Buji Ateşlemeli Motorlarda Yakıta Asetilen Gazı İlavesinin Egzoz Emisyonlarına Etkisinin Deneysel Analizi. Bitlis Eren Üniversitesi Fen Bilimleri Dergisi, 3 (1): 24-34.

[12] Lakshmanan T., Nagarajan G. 2010. Experimentalinvestigation on dualfueloperation of acetylene in a DI diesel engine. Fuel Processing Technology, 91: 496-503.

[13] Lakshmanan T., Nagarajan G. 2010. Experimental investigation of timed manifold injection of acetylene in direct injection diesel engine in dual fuel mode. Energy, 35: 3172-3178.

[14] Asetilen Gazı Kullanımında Dikkat Edilecek Hususlar, 2019. http://www.lindegaz.com.tr/tr/images/asetilen\%20kullanimi\%20flyer\%20con\%20\%281\%29_tc m504-258999.pdf) (Erişim tarihi: 10.06.2019). 
[15] İlhak İ.M. 2018. Buji ateşlemeli bir motorda asetilen gazının motor performansına ve emisyonlarına etkisinin incelenmesi. Doktora Tezi, Erciyes Üniversitesi Fen Bilimleri Enstitüsü, Kayseri.

[16] OPET, Yakıt özellikleri, 2018. https://www.opet.com.tr/files/PDF/Urun/Ultra-Force-MotorinUrun-teknik-ozellikleri.pdf. (Erişim tarihi: 10.06.2019).

[17] Ozcan H. 2010. Hydrogen enrichment effects on these condlaw analysis of a lean burn natural gas engine. International Journal of Hydrogen Energy, 35 (3): 1443-1452.

[18] Papagiannakis R.G., Rakopoulos C.D., Hountalas D.T., Rakopoulos D.C. 2010. Emission characteristics of high speed, dualfuel, compressionignition engine operating in a widerange of natural gas/diesel fuel proportions. 7th International Symposium on Alcohol Fuels, 89 (7): 1397 1406.

[19] Akçay M., Özer S. 2019. Experimental investigation on performance and emission characteristics of a CI diesel engine fueled with fusel oil/diesel fuel blends. Journal Energy Sources, Part A: Recovery, Utilization, and Environmental Effects, https://doi.org/10.1080/15567036.2019.1689317

[20] Roshan R., Naveen K. 2019.The utilization of n-butanol/dieselblends in Acetylene Dual Fuel Engine Author links open over lay panel. Energy Reports, 5: 1030-1040.

[21] Pravadalığlu S. 2019. Yerinde enerji Üretimi-Kojenerasyon Sistemleri, http://www.emo.org.tr/ekler/04aa4e179069a80_ek.pdf. (Erişim tarihi: 09.09.2020).

[22] Temizer İ., İlk1lıç C., Öner C. 2016. Dizel Motor Egzoz Sistemi için Termoelektrik Jeneratör Uygulaması ve Akış Analizi. Afyon Kocatepe Üniversitesi Fen ve Mühendislik Bilimleri Dergisi, 16: 431-445.

[23] Şimşek D., Çolak Y.N. 2019. Biyodizel/Propanol Yakıt Karışımlarının Dizel Motor Emisyonlarına Etkisinin İncelenmesi. El-Cezeri Fen ve Mühendislik Dergisi, 6 (1): 166-174.

[24] Aktas A., Doğan O. 2010. Çift Yakıtlı Bir Dizel Motorda LPG Yüzdesinin Performans ve Egsoz Emisyonlarına Etkisi. Gazi Üniversitesi, Mühendislik-Mimarlık Fakültesi Dergisi, 25 (1): 171178.

[25] Pritinika B., Murugan S., Nagarajan G. 2014. Dual fuel operation of used transformer oil with acetylene in a DI diesel engine. Energy Conversion and Management, 87: 840-847.

[26] Balasubramanian K., Krishnan P. 2019. Effect of acetylene addition in safflower biodiesel fueled CI engine an experimental study. Energy Sources Part A-Recovery Utilization and Environmental Effects, DOI: 10.1080/15567036.2019.1678700.

[27] Yan W., Pan W., Sheikh M., Farhan J., Yi Li L. 2019.Effect of post-injection on combustion an dexhauste missions in DI diesel engine. Fuel, 258: 116-131.

[28] Çelik M.B., Şimşek D. 2014. The determination of optimum injection pressure in an engine fuelled with soybean biodiesel/diesel blend. Thermal Science 18 (1): 229-238.

[29] Balasubramanian K., Purushothaman K. 2019. Effect of acetylene addition on performance, emission and combustion characteristics of neem biodiesel and corn biodiesel-fueled CI engine. Journal of Thermal Analysis And Calorimetry, 138: 1405-1414. 